\title{
Letting the Field Show us the Way - a Mixed Methodology to Understand Judicial Decision Making
}

\author{
Andreia de Castro-Rodrigues*, Ana Sacau
}

Social ,Human Sciences College, University Fernando Pessoa, Porto, Portugal

\begin{abstract}
The purpose of this article is to describe the methodology used in three studies to obtain data from a Portuguese Criminal Court in order to undertake a psychological analysis of judicial decision-making in the criminal justice system to gain a better understanding of the phenomenon. Because information about the Portuguese criminal system is scarce, the design and definition of the studies was adapted from literature and our experience derived from the contact with the field. We explain how this methodology arose, particularly how it was designed and formulated through contact with the field and with the actors - the judges - in the decision making process that we were studying. This approximated an ethnographic type of approach to reality. We focused on criminal court judges as the starting point and source of our data.
\end{abstract}

Keywords Mixed Methodological Design, Qualitative Paradigm, Judges, Judicial Decision Making, Judicial Psychology

\section{Introduction}

This article presents the process of defining the methodol ogical design of a research project. The methodology, mixed although predominantly qualitative, is a way of gaining insight into the topic of judges' decision-making processes in the criminal justice system.

Presently criminal justice in Portugal has greater visibility and exposure as well as misunderstanding. The description of criminal justice in Portugal in the popular media is simplistic and not grounded in an analysis of the realities of the processes related to trials. Consequently, we consider it to be especially relevant to add knowledge based on scientific investigation carried out in the natural environ ment of the actual phenomenon so as to provide authoritative information and to correct misinformation not rarely spread by the mass media. Solimine and Wheatley[1] argue that a clear limitation of most studies in this area is to analyze judges decisions and not the process and background of these decisions, we add. Then, traditional scholarship viewpoints about sentencing might not be the best way to understand the rationale behind it as judicial decisions are not purely rational and legal-based but social[2].

We maintain that a psychological analysis of the process will provide a valuable contribution by introducing new

* Corresponding author:

andreiar@u fp.edu.pt (Andreia de Castro-Rodrigues)

Published online at http://journal.sapub.org/ijap

Copyright (C) 2012 Scientific \& Academic Publishing. All Rights Reserved understandings of and meanings to judges' decision making. We share Wrightsman's [3] assumption that psychology can add an important contribution to the analysis of judicial decision-making, since judges' values serve as a "kind of filter" (p. 213) when they analyse and interpret the facts of a case. With judicial decision making as our starting point we concluded that contact with the field and reality was essential to guide our methodological options in matters of goal setting, methods and data collection techniques.

Therefore, the design of the three studies evolved from an ethnographic approach to our research objective prescribed by qualitative methodologies in which methods are marked by an open attitude towards the object in order to respond to the diversity of everyday life [4]. The premise that guided our choice for this type of approach was stated by Denzin and Lincoln[5], "qualitative researchers study things attempting to make sense of, or to interpret, phenomena in terms of the mean ings people bring to them" (p.5). Other issues related to our social understanding of the world and knowledge itself, also contributed to our choice in terms of methodology, due to the fact that qualitative research " ... is oriented towards analysing concrete cases in their temporal and local particularity and starting from people's expressions and activities in their local contexts" (p.21)[4]. The judicial decision-making is a complex process that is not possible to be reduced to a simple application of the law.

Moreover, judges are not mere law transmitters but judicial and also social interpreters of it. It is therefore important that the scholars who analyse judges' decision making process use mixed methods to collect and analyze data that allow us not only to quantify the influence of 
several factors on sentencing but also understand the meanings involved in that process.

An ethnographic approach to the object allowed us to realize, as we'll show across this paper, that the analys is of formal documents as the final judgment document is not enough to understand the implic it aspects of the decision, its rationale.

As we'll present in this paper, once the judicial decision-making is a very formal process, a prior approximation is required in order to avoid the specific limitations of the research in this area. Our approach allowed us to redefine the initial methodological choices from a content analysis of final judgment document to a mixed methodology that included interviews, questionnaires and a content analysis of a spontaneous moment of the sentence reading (or speech) when judges transmit to the offender what they consider important to pass.

\section{Objective}

The principal objective of th is research is to add knowled ge about this process by analysing and understanding judges' decision making by using psychology. A major concern was to limit the scope of the inquiry in order to allow us to focus on the subject more sharply. One of the decisions we made to narrow our focus was to limit our studies to the criminal area. We concluded that criminal justice has a wider variety of situations, it is more complex and that it might provide us with more insight into important aspects of decision making.

Our research fits none of the five categories described by Creswe11[6] exclusively namely, biography, phenomenology, grounded theory, ethnography and case study. Ours is a phenomenological study incorporating grounded theory, which emerged from an ethnographic approach to our objective. Creswell's description of phenomenology provides us with a starting point in that our goal is to understand as much as possible about the essence of the experiences related to judicial decision making, trying to examine them and the meanings they entail for the actors at stake the judges. This approach had to be expanded because of the absence of theoretical knowledge about the Portuguese context. Consequently, we use grounded theory as our framework. This means that ultimately we have to create a theory about this particular subject in this particular environment based on the data collected from the field[6]. Because there are no simple explanations for the social phenomena, we intend to capture the judges' multiple perspectives around judicial decision making, locating them within their nets[7]. This also necessitates utilizing methodological choices emerg ing from an ethnography-like approach to the field.

In summary, the choices we made to conduct our three studies resulted from our continued observation over time and from our contact with the reality of the judicial decision making process in the criminal court and its actors.

Your goal is to adhere to this paper in appearance as closely as possible.

\section{Methodology}

\subsection{Approaching the Field}

Go ing onto the field and refining the methodology of our research our field was the Criminal Court of Porto, Portugal happened in November 2008. We began our research by obtaining all the necess ary authorizations to attend the court and record the information needed. The first requests were consistent with our initial goal, which was access the judgement and sentence documents of several judges, that is, the formal written documentation concerning verdicts. Towards the end of November we began the research by observing the dynamics of the court as well as reading those documents. We soon realized this might reveal additional points of interest and cause us to reorganise our initial methodological outline.

This happened. By having access granted to the formal judgements on sentencing and reviewing the pertinent articles of the Código do Processo Penal Português[8], which define the procedure, we understood that judgements on sentencing are to a large extent defined and structured by article $374 .^{\circ}$ [Requirements of the judgment on sentencing], although some variations in style are allowed from judge to judge, permitting them to adapt their informal oral statements which are also permitted but not defined by the article.

As a result of this realization as well as the conclusions of other authors ${ }^{1}$ [9] we revie wed and rev is ed our original plan, which was to make exhaustive content analys is of the formal sentencing documents. The reason for this was that we concluded that the written documents consisted of primarily legal information in accord with a preset legal pattern. Consequently, we concluded that such an analys is would not provide us with a greater understanding of the judges' decision making process. From our direct observation and contact with the judges as our privileged source of data for our planned analysis of judges' decision making, we concluded that the formal sentences did not accurately reflect the process and the dynamic of decision-making. Although the formal sentences complied with the requirements of the law it became apparent to us, through our observations of the procedure and our conversations with judges individually, that they did not provide us with an accurate understanding of judicial decision making. Not rarely, we realized that the sentence resulted more as a legal way of justifying and contextualising the decision taken, than as a 'map' of the decision making process.

\subsection{Redefining Objectives and an adequate Methodology}

Having set aside a study centred on the content analys is of the formal judgements on sentencing other aspects of the process materialized as potential areas of interest through the ethnographic approach. The ethnographic approach gained support as we noticed that encouragement and 
receptivity to our work from the field was much higher than we had expected. Consequently we became aware of the opportunity of carrying out in loco research, thus getting to know this reality in a close to ethnographic design.

We refined our methodological design with the goal of studying the behaviour of a given group, in this case, a professional group of judges. This methodology consists of the researcher considering the observable and learned behavioural patterns, habits and lifestyles of the subjects (Harris, 1968, in [6]). This method that Agar (1980, in[6]) defends, represents not only a process but also a product of the research by itself. It took us approximately nine months, which is in accordance with the interval of six to twelve months defined as adequate for conducting such a study[6].

We used observation, one of the techniques of ethnography. At times we assumed a passive participant attitude. At other times, in the formal judgements on sentencing, we assumed a non-participant attitude, attentive to the different moments of the trial and to all that surrounded us. We were receptive to anything that would capture our attention and that might be of interest to research. As a result of these observations and experiences we reformulated the methodological procedures, as well as the goals of the research. This process took the shape of an 'immersion' for the researcher, who dived into "in the everyday world of their research participants to grasp the visceral, emotional, and unconscious aspects of group life" (p.756)[6].

Naturally, this process had the purpose of incorporating this information in the definition of the goals of this research, in its methodological design, in the construction of data collection instruments and the grid for reading and analysing the collected data.

Thus, the actual contact with the field and the concrete reality and its actors made us modify our initial goal. At the beginning of the investigation, our aim was to understand the judges' decision making in terms of the frequently studied extra-legal aspects that may influence the sentence decisions. However, over time we ended up changing it into gaining insight and comprehension about the process in terms of judges' more implicit aspects. This new approach aimed to disclose judges' personal opinions on political and legal levels and also beliefs about attributions of crime, their orig ins, the criminal individual, social differences, the diversity of social-legal goals, etc.

We had the conviction that this entailed a difficult goal, since it called for determining implicit dimensions lying in these processes and as it concerned individuals, that is judges, who were potentially and also expectedly well guarded particularly in light of the exposure by the media to Portuguese criminal justice at that time. This led to two decisions: on the one hand it guided us to choose a predominantly qualitative approach, on the other hand it determined to understand our objects, that is the decisions, from different perspectives, with a mixed methodology in order to sum them up gradually to complete the best achievable 'picture'.
Assuming that the methodological choices should be taken in view of what one is trying to comprehend[10] we settled on the adequacy of a mainly qualitative approach to our goals of grasping the 'other' and the implicit dimensions of his/her decisions. This approach enables analysing thematic areas in the settings in which they arise and thereby allows a perspective on those issues from the inside[6]. Qualitative research mingles a set of techniques especially adjusted to everyday-life issues, whether experiential or professional, due to the fact that it allows rich descriptions[11]. In the context of qualitative methodology narrative writing, long passages exposing different perspectives on the analysed subject and the inclusion of quotations from the actors arise as a way to represent them more truthfully and allow an accurate, complex and holistic image of the phenomenon[6]. This approach also postulates that the research should be carried out without rigid and stiff guidelines, the methods being open and permeable to the object[4]. Additionally it postulates that the designs of the studies benefit from being developed in the course of the research bearing in mind what is starting to make sense and gain meaning[6]. Also the analysis should guide itself by real phenomena in their space and time context and according to the signs and actions of real people interacting with their real world[4]. Qualitative methodology studies objects in their complexity and as a whole, in everyday-life, and intentionally renounces reducing them to a bundle of particular variables[4]. Other reasons for our choice include: the nature of our object, our angle of interest being 'how' and not 'why'[6]; seeking to understand and describe a phenomenon; trying to interpret and grasp the meanings the actors themselves attribute to it[5]; and not having as our main interest establishing relations, doing comparisons or disclosing causes and effects.

In summary, as pointed out by Creswell[6], the choice for an eminently qualitative approach is valid because of: the fact that this topic has to be explored in order to create theoretical frames empirically rather than confirming or not a certain pre-existing theory; the importance of presenting a detailed view of the subject, instead of a wide-angle and distant one; the availability of time and the possibility of carrying out an extensive data collection and an exhaustive analysis of the data set; the fact of emphasizing the researcher's active learning attitude when 'telling the story' rather than evaluating it fro $m$ the angle of 'the expert'.

This research is based on a qualitative paradigm but uses a mixed methodology because we share Hammersley's view that our methodological choices should bear in mind evaluating a series of actors, but not depend "on ideological commitment to one methodological paradig $\mathrm{m}$ or another" (p.12, as cited in[10]).

Additionally as Ercikan and Roth[12] pointed out, the polarization of methodologies into qualitative and quantitative is unnecessary and the real issue that researchers should consider is the adjustments to their data, starting points and questions, considering the use of the 
mu ltip le perspectives and ways to gather data.

Hence, the empirical part of this research is composed of three studies, the first and third of them with qualitative data and the second including quantitative data, as follows.

\section{The Emergence of the Three Studies}

Now that we have described the framework in terms of the research paradigm we intend to briefly describe the three studies, namely the logic of their emergence in terms of their adequacy to our goal as well as the way in which they complement each other and act retroactively.

\subsection{The Way each Responds to the Object}

We put a big amount of time in court trying to understand the best methods to access the processes of judges' decision making due to the fact (explained earlier) that the analysis of some sentence written documents allowed us to conclude that these didn't provide insight into the decision making process itself. Consequently we decided to invest time in observing the procedures we had access to as a way to establish where there may be significant issues that would bring us closer to the decision making process from different angles, especially given the internal, personal nature that hinders an easy access to it.

As a result of this investment three studies emerged as described below.

\section{Study I}

Study I consists of the content analysis of 93 transcriptions of oral sentencing remarks, during sentences pronouncements, from the different judges of the court. We realized that there are different styles used at this moment in which the decision is pronounced; many of them included important aspects that had motivated the decision, explaining them in other than legal terms. They revealed the way each judge responds and interprets the broader formulation allowed them at this moment of the trial by the Portuguese Penal Process Code[8]. The two goals guiding this study are: a) to understand how judges interpret and apply the discretion provided by the void, that is silence, of the Portuguese Penal Process Code[8] on this subject ${ }^{2}$ and the range of is sues the judge might address $s^{3}$; b) to identify the issues emphasized at that moment of explaining the sentence as possible indicators of particularly important aspects for the decision that the judge considered important to share with the defendant.

Study II

Study II includes conducting a statistical analys is of data generated by a questionnaire ${ }^{4}$ designed by us and that combines information provided by Study I with data from the literature about aspects related to the judges' decision making. This questionnaire considers areas such as:

- Socio-demographic features of the aggressor: Gender, age, health situation, family/marital status, socio-economic situation, factor constellations;

- Aspects related to the judge: Gender, age, political ideology, years of experience (rural and urban), penal ideologies, attributions related to criminality (causes, relapse/recidivism, danger or risk assessment and crime control, justifications for crime), attributions on sentencing and the Portuguese legal context, class attributions (features of a good judge, causes for disagreement a mong judges);

- Aspects related to the transgressing act, the transgressor and the victim: Features of the crime, aggravation and attenuation, transgressor's behaviour standing at court, criminal background, society's reaction;

- Aspects related to different penalties: Attributions to the adjustment of various penalties to different crimes, attributions to the adjustment of various penalties to different sententious goals.

Study III

Study III consists of the content analys is of the twelve semi-structured and exhaustive interviews for the purpose of analysing the issues that emerged from the two earlier studies. Additionally, it is also our goal to provide the opportunity to the actors of this decision making process to explain their own meaning to this complex data set. The script of the interview includes the following domains:

- The task of judging and the sentencing;

- Prison sentencing;

- The behaviour of the defendant standing at court;

- The Portuguese penal system.

\subsection{The Way the Studies complement each other the Whole they compose}

As we have stated above these three studies compose a mixed methodology, combining both quantitative as well as qualitative research dimensions, accentuating the qualitative one in the way the object was defined and approached. Although favouring one methodology over the other is in our judgement inevitable since any paradigm encompasses both the role of the researcher and the legitimacy space of the research[13], we decided to include both dimensions in our research as a way to better understand our subject. Thus, we share the opinion of various researchers who state that both methods as techniques should be weighted and chosen as a result of the answers that are being researched, i.e. depending on the research object[10].

Consequently, we tried to devise a methodology that would capture as much as possible and through different forms the judges' judicial decision, by 'forcing' them to give us data about that process in various ways: in a direct way, through a questionnaire and an exhaustive interview, and in an indirect manner, through our analysis of the 'extra-sentence' the undocumented oral statement portion of the sentences pronouncements.

The first technique 'forces' the judges into making a choice projecting their way of thinking, through pre-set closed options, based on the existing factors found in the literature and on data resulting from our observations and remarks influencing the decisions.

The second technique, allows an unrestrained and free exploration of a long script that compiled the questions 
arising from the two earlier studies. This study had a twofold objective. First, by providing the judges an active voice in the entire process of comprehension and interpretation of sentencing reality, allowing them to make sense out of it. Second, also making them project their thoughts in a less restrictive way than the questionnaire, in terms of social desirability. Specifically because an interview, particularly a long one, results in a situation in which, in order to give answers, one has to think out loud about his/her own position.

The third technique tries to access other more implicit aspects of the judges' sentencing namely the way judges project themselves, in terms of exposing to the defendant the parts of their decision they consider most important, and also in terms of how these judges consider they should implement the undocumented oral portion of the sentence pronouncement.

\section{Conclusions}

One of the criticisms about psychological research about sentencing, as we previously said, is that "the empirical studies analyze only the judges' votes and decisions" (p.900)[1]. This approach might imply the problem of not been able to reveal what underlies those decisions, which is our main purpose. As advocated by Goodman-Delahunty and Sporer[16] "concerns have been raised that reasons articulated in judicial decisions are crafted to withstand appeal and to fit the parameters of model defensible legal guideline judgments, but may not correspond with the decision making process itself' (p.20).

Traditionally, studies about judicial decision-making used an input-output methodological design[14] in which the decision is a result of the influence of a set of legal and/or extra-legal variables[15]. These studies usually focused on finding discrimination, disparity or even discretion in criminal judgements. These classical studies frequently looked for the impact that several characteristics from the offender (age, gender, race and socio-economic status, a mong others) but also related to the sentencer (from pers onal attitudes to penal philosophies), the victim and the context may have over sentencing decisions (see[16] for a review).

More recently, several authors have been employing experimental methods, for example, presenting judges simu lated cases for them to decide[17]. Th is author justifies her option advocating that the use of simulated cases has the potential of avoiding the limitations of studies with real situations in terms of internal validity. However, these studies recurring to artificial situations suffer from another non-less important problem, that is, their external validity. These artificial situations, by its nature, can't include some aspects of real contexts that might be important in the decision-making processes such as the behaviour of the offender and other trial dynamics. Some studies have been focusing in the influence of some offender characteristics such as their physical appearance, their facial expressions, their emotional behaviours, etc.[16]. Other criticis $m$ to the experimental studies is that they often use law students' samples or other individuals that aren't judges. The obvious distinctions between these groups and judges may jeopardize the inferences that can be drawn from the studies results.

Some other recent studies have been tried to complement these methodologies with other techniques, such as interviews [18] in order to minimize these limitations.

Considering the complex issue we are dealing with and the several methodological limitations each approach might have, we tried to find a way to maximize the potentialities of the possible techniques. In the words of Graycar[19], our aim is to gain "more insight into what judges know, how they know it, how this shapes the construction of reality in judgments, and how this is all affected by gender, race and other aspects of identity" (p.11).

Considering the specific context, the state of art of sentencing research in Portugal as well as our objectives, we considered that an experimental design with artificial situations would not be adequate and that a more exploratory research would be more suitable. The methodological design that we present here enables us to describe relevant and underlying elements and features from sentencing decisions, through a context-based approach.

Summarising, the purpose of setting up a mixed methodology in this way was to make it possible to gain access to the phenomena of judges' sentencing decision making in an holistic and complex way, capturing it in its various dimensions[6]. Putting it differently, analysing this phenomenon from different and complementary 'angles', as it turned out to be.

\section{ACKNOWLEDGEMENTS}

This article was funded by FCT (Foundation for Science and Technology), as an Investigation Scholarship of QREN POPH Typology 4.1Advanced Training subsidized for the European Social Fund and national funds of MCTES, with the reference PTDC/PSI/65044/2006.

\section{Notes}

1. Recorring to a content analysis of sentences these authors verified among other things that the sentence decision of the judges relates predominantly to legal references.

2. "When the court returns to the courtroom, the sentence is publicly read by the president or by one of the others judges. The reading of the report must be omitted. The reading of the grounding or, if this is to extensive, of its summary, as well as of the legal provisions, is mandatory, otherwise must be void." CPP, article 372, n 3.

3. "After the reading of the conviction sentence, the 
president, when he finds it convenient, gives the defendant a brief allocution, urging him to correct hims elf." CPP, article 375. n.2.

4. "Judicial decision making analysis questionnaire", Rodrigues, A. \& Sacau, A. (2009, not published).

\section{REFERENCES}

[1] Michael E. Solimine and Susan E. Wheatley, "Rethinking Feminist Judging,", Indiana Law Journal, vol. 70, iss. 3, article 4, pp. 891-920, 1995. Available at: http://www.repository.law.indiana.edu/ilj/vol70/iss3/4

[2] Cyrus Tata, Accountability for the sentencing decision process: Towards a new understanding, in Cyrus Tata and Neil Hutton (Eds), Sentencing and Society, Ashgate, pp. 399-420, 2002.

[3] Lawrence S. Wrightsman, Judicial Decision-making: Is Psychology Relevant? Perspectives in Law and Psychology, Volume 11, Plenum Publishers, New York, 1999.

[4] Uwe Flick, An Introduction to Qualitative Research, Sage Publications, United Kindom, 1998.

[5] Norman K. Denzin, and Yvonna S. Lincoln, (Eds.), Strategies of Qualitative Inquiry, Sage Publications, USA, 1998.

[6] John W. Creswell, Qualitative Inquiry and Research Design: Choosing among Five Traditions, Sage Publications, USA, 1998.

[7] Juliet M. Corbin and Anselm L. Strauss, Basics of Qualitative Research: Techniques and Procedures for Developing Grounded Theory, 3rd ed, Sage Publications, USA, 2008.

[8] Portuguese Penal Process Code, 2007, Online Available: http://www.legix.pt/docs/CPP.pdf

[9] Inês B. Henriques and Lúcia G. Pais, "Compreender como os magistrados compreendem: um estudo do processo de tomada de decisão jurídico-judicial'[Understanding how Judges Understand: a Study of the Judicial Decision-Making Process], in Actas da XI Conferência Internacional Avaliação Psicológica: Formas e Contextos, pp. 881-889, 2006.

[10] David Silverman, Doing Qualitative Research A Practical Handbook, Sage Publications, United Kingdom, 2000.

[11] Michael Bloor, “Addressing Social Problems Through Qualitative Research", in David Silverman, ed., Qualitative Research Theory, Method and Practice, pp. 305-324, Sage Publications, United Kingdom, 1998.

[12] Kadriye Ercikan and Wolff-Michael Roth, "What Good is Polarizing Research into Qualitative and Quantitative?", Educational Research, vol. 35, no. 5, pp. 14-23, 2006.

[13] Sharlene N. Hesse-Biber and Patricia Leavy, eds., Approaches to Qualitative Research: a Reader on Theory and Practice, Oxford University Press, USA, 2004.

[14] John Hogarth, Sentencing as a human process, University of Toronto Press in association with the Centre of Criminology, Canada, 1971.

[15] James L. Gibson, "Judges' role orientations, attitudes, and decisions: an interactive model" The American Political Science Review, 72, 3, pp. 911-924, 1978.

[16] Jane Goodman-Delahunty and Siegfried L. Sporer, "Unconscious influences in sentencing decisions: a research review of psychological sources of disparity", Australian Journal of Forensic Sciences, 42, 1, March, pp. 19-36, 2010.

[17] Mandeep K. Dhami, "From Discretion to Disagreement: Explaining Disparities in Judges' Pretrial Decisions", Behavioral Sciences and the Law, 23, pp. 367-386, 2005.

[18] Niamh Maguire, "Consistency in sentencing", Judicial Studies Institute Journal, 2, pp. 14-54, 2010.

[19] Regina Graycar, "The gender of judgments: some reflections on 'bias"”, UBC Law Review, 32, 1, pp. 1-21, 1998. 